\title{
MEASUREMENT OF RESIDUAL STRESSES OF LOCOMOTIVE WHEEL TREADS DURING THE MANUFACTURING TECHNOLOGICAL CYCLE
}

\author{
Vitaly V. MURAVEV, Olga V. MURAVEVA*, Ludmila V. VOLKOVA \\ Kalashnikov Izhevsk State Technical University \\ *Udmurt Scientific Center of Ural Branch of Russian Academy of Sciences \\ Milan SÁGA, Zuzana SÁGOVÁ
University of Žilina
}

\begin{abstract}
:
The production of two-wheeled rolling stock represents, at first glance, a simple assembly process that significantly affects the overall functionality and safety of the vehicle. This is due to residual stresses that arise after assembly by pressing the wheel on the axle. The state of stress after assembly remains in the design has a decisive influence on the load-bearing capacity of the two-wheel drive, its lifespan but also the transfer of the pulling force in the case of locomotives. Therefore, it is very important to find suitable methods for determining residual stresses. Numerical and experimental approaches are already in place to gain information on the state of stress after compression, or during a real operation. The developed techniques and tools for estimation of residual stresses in locomotive wheel treads based on the acoustoelasticity effect using electromagnetic acoustic transformation are described in the paper. The original results of residual stress measurement in the treads during a technological cycle of locomotive wheel pair manufacturing are presented.
\end{abstract}

Key words: tread railway wheels, acoustoelasticity, electromagnetic acoustic transformation, residual stresses

\section{INTRODUCTION}

A tread of locomotive wheel is the most critical element of the wheel pair interacting with a rail track. Tread destruction is unacceptable as it creates a threat to traffic safety. Tread reliability is defined not only by metal quality and its strength but also by residual stresses. The locomotive wheel tread is exposed to pressure shaping, cutting and heat treating (temper hardening) during the manufacturing process $[1,2,25]$. Heat treatment leads to development of the complicated stress-strain state, and the next interference fit on the wheel center provides appearance of additional strain stresses [1, 2].

As a result of the tread fitting on the wheel center the technological residual stresses caused by pressing, rolling, and hardening are summarized with the mechanical tensile stresses associated with the interference during parts mating. The interference $\mathrm{N}$ is a positive difference between shaft diameters and the hole of the fit-on detail:

$$
N=d_{2}-d_{1}
$$

where:

$d_{2}$ is a wheel center diameter;

$d_{1}$ is an inner tread diameter.

The interference is realized by shrink fit, affecting by forces $F$ on the tread heated to $250-300^{\circ} \mathrm{C}$ and on the cold wheel center with the diameter difference of $d_{2}-d_{1}=1.2-1.6 \mathrm{~mm}$. While heating the inner tread diameter is growing and exceeds the rim diameter by 1.3-1.7 mm, providing connection between the wheel center and the tread up to constructional limit. The contact circumferential pressures $P$ tightly compressing the wheel center are forming during tread slow cooling (Fig. 1). In case of such fitting, bonding strength is achieved by means of the mating part deformation appearing during joining process. The contact pressure $p$ leads to appearance of normal radial and circumferential stresses in the mating parts. After the fitting, the inner surface nearby connection has the highest values of the circumferential tensile stresses in the tread. In these circumstances the compressive radial stresses are low.

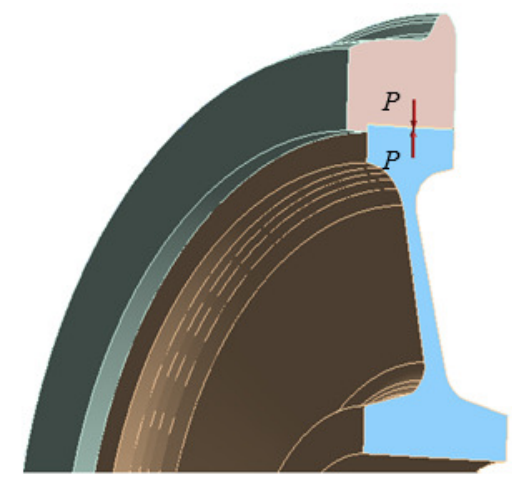

Fig. 1 Forces acting on the surface of the mating parts during an interference fit after pressing-in 
Static and cyclic external pressures change stress state distribution in the wheel during its operation. Stress relaxation causes interference weakening and creeping of the tread. Cracks and tread breaking can appear during the operation under high level of residual stresses and concentrator existence $[3,4,5]$.

The purpose of the paper was estimation of the residual stress level around the circumference and through the thickness of the tread during the manufacturing process of locomotive wheel pairs.

\section{METHODS AND TECHNIQUES}

A wide arsenal of nondestructive physical magnetic $[6,7]$ and acoustic $[8,9,10,11,12,13]$ methods and techniques of nondestructive testing are used to solve the problems of determining the stress-strain behavior of constructional materials $[23,24]$. The most informative and perspective nondestructive method for evaluation of residual stresses is acoustic strain measurement based on measurement of the characteristics of elastic waves in the object under inspection. The stressed state of the material of a tread was estimated by the acoustoelasticity method. The method is based on the change of the propagation velocity of acoustic waves depending on the value of the stressed state of a material during the scanning of a tread with transversal radially and tangentially polarized waves along the width. On the assumption that the stressed state of a tread is described by the tangential stresses at near zero radial stresses, it is possible to use the formula of acoustoelasticity for a uniaxial stressed state in the following form [1]:

$$
\sigma=D\left(a-a_{0}\right)=D a-D a_{0}
$$

where:

$a=\frac{t_{2}-t_{1}}{t_{2}}, a_{0}=\frac{t_{02}-t_{01}}{t_{02}}$,

where:

$D a$ is the material acoustic anisotropy factor caused by the contribution of stressed state, rolling texture, and structure after thermal treatment,

$D a_{0}$ is a factor that taking the contribution of structure and texture into account,

$t_{1}$ and $t_{2}$ are the time delays of radial and tangential polarized shear waves, respectively,

$t_{01}$ and $t_{02}$ are the time delays of shear waves in the absence of stressed state,

$D$ is the acoustoelastic coefficient (obtained experimentally for the studied carbon steel $D=-140 \mathrm{GPa}$ ).

The distribution of the factor $D a$ along the thickness of a tread is determined by the specifics of the formation of a structure and a rolling texture under the thermal treatment of the material of a tread. The value of $D a_{0}$ is -35 $\mathrm{MPa}$ near the tread surface and $+45 \mathrm{MPa}$ in the center of a tread and decreases when approaching the seating surface. The comparison of the distribution of $D a_{0}$ values for a tread fragment with the results of the studies of $D a$ for free treads shows that the differences between them are nearly 50-100 $\mathrm{MPa}$, which corresponds to the contribution of residual stresses in a tread; this fact should be taken into consideration when estimating true residual stresses [2].
Most of the acoustoelasticity techniques are based on methods involving contact piezoelectric transducers, where high requirements are imposed on the dimensions, flatness of entry and reflecting surfaces, contact quality, etc. The insufficiently high accuracy of techniques and the necessity of standard sample usage set bounds to their application. One of the approaches to solving problems of the stress-strain behavior and structure of metals is application of electromagnetic-acoustic (EMA) technique of ultrasound pulse excitation and registration $[14,15,16,17$, $18,19,22,25]$. Contactless EMA method of excitation-receipt does not require application of the contact liquid, thus giving the possibility to perform control procedures for rough and contaminated surfaces of objects, at high and low temperatures and for objects moving at high speeds. It is important that EMA transducers allow for generating different types of waves with various polarization. The essential advantage of EMA transducers is their noncontact nature, which allows one to receive multiple reflection series due to the absence of losses at the transducer-object boundaries and, therefore, to improve the measuring accuracy of such parameters as acoustic wave velocity and attenuation, and also to use the amplitude of EMA conversion as an additional informative parameter for the evaluation of residual stresses in metal products. The main disadvantage of the EMA transducers is low conversion efficiency in comparison with traditional piezoelectric transducers. Increase of the EMA transducer efficiency can be achieved due to increase of the value of magnetic bias field, the amplitude of probe pulse and the sensitivity of receive path.

The emission of acoustic waves in metals in the presence of the electrodynamic interaction mechanism in the radiation mode is caused by the appearance of elastic stresses (Ampere forces $F_{A}$ ) in the near-surface layer of an object. They are determined by the interaction between eddy currents $i_{e}$ with the length of $d l$ and induction of magnetic bias field $B_{0}$ (Ampere force $F_{A}$ ) [20]:

$$
F_{A}=i_{e}\left[d l \cdot B_{0}\right]
$$

The wave polarization is provided due to the mutual orientation of magnetic bias field $B_{0}$ and inductor current direction.

The origin of elastic stress takes place in the thin subsurface layer of an object defined by skin depth $\delta$ :

$$
\delta=\sqrt{2 / \omega \mu_{0} \mu \sigma}
$$

where:

$\mu_{0}=4 \pi \cdot 10^{-7} \mathrm{H} / \mathrm{m}$,

$\mu$ is relative magnetic permeability,

$\sigma$ is conductivity, $\omega$ is wave circular frequency.

The acoustic wave pulses rereflected multiply over the tread width are received by the same transducer due to the back interaction (electromagnetic fields generated by eddy currents $j$ in the subsurface layer of the object, oscillating at velocity $V$ in the magnetic bias field with induction $B_{0}[20]$ :

$$
\vec{\jmath}=\sigma\left[V \cdot B_{0}\right]
$$




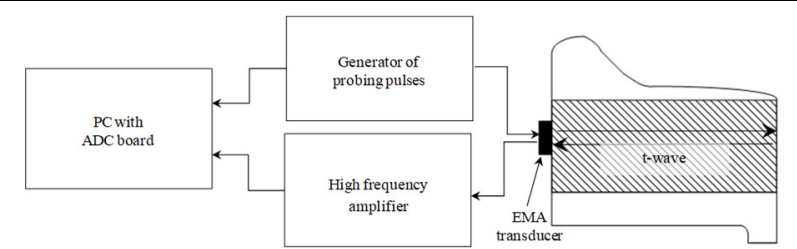

a

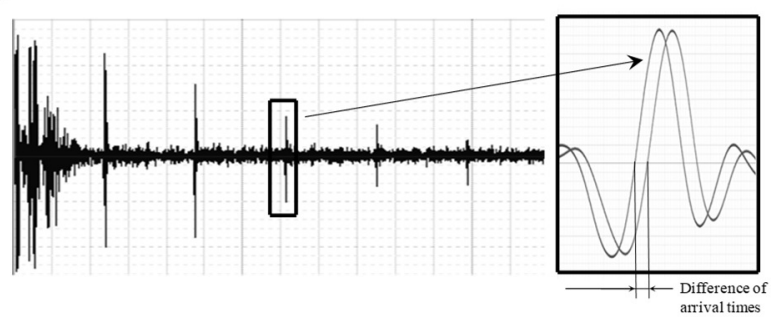

b

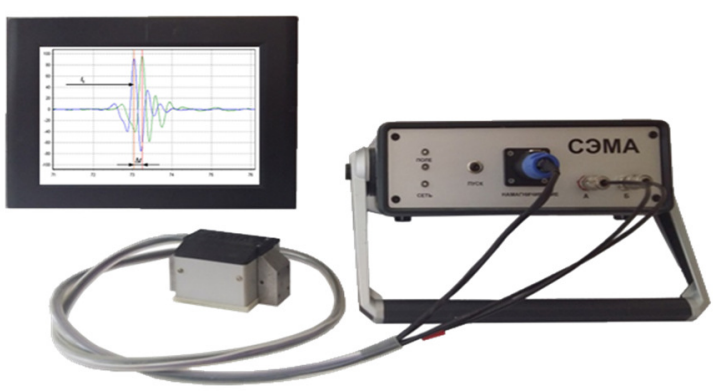

C

Fig. 2 Structural diagram of the experimental apparatus (a), bottom signals of transverse waves polarized in the circumferential and radial directions in the third reflection (b), foto of SEMA structurescope (c)

The stressed state in treads was estimated using the developed SEMA structurescope (Fig. 2). Shear waves were excited and received using a specialized EMA transducer. The SEMA structuroscope includes a generator of electric pulses that forms a powerful probing electric pulse, an EMA transducer that excites and receives short acoustic pulses of transverse waves, an amplifier, and an ADC circuit board that is built into a computer that displays pulses reflected from the tread width. The recorded signals are processed with a specialized Prince VIII piece of software that makes it possible to compare the pulses of two received signals and to measure their amplitudes and their time difference.

The structurescope has the following basic technical specifications:

- An amplitude of the probe pulse generator is $2.0 \mathrm{kV}$;

- An operating frequency is $2.5 \mathrm{MHz}$;

- An amplifier bandwidth is 0.6-6.6 MHz;

- A coefficient of amplification is $66 \mathrm{~dB}$;

- An AD converter has resolution of 8 bit, a sample rate of $500 \mathrm{MHz}$ and a bandwidth of $100 \mathrm{MHz}$.

Specialized software allows observing multiple reflection echograms of two shear waves with mutually perpendicular polarization planes on the device display simultaneously. The application of coherent time accumulation and autocorrelation methods for signal processing gave an opportunity to provide stress estimation accuracy up to \pm 3 MPa.

The measurements were performed in several tread cross sections by installing an EMA transducer on the internal side surface at a distance from 10 to $55 \mathrm{~mm}$ from the tread surface for free tread und under locomotive (Fig. 3). Time of one measurement does not exceed 15 seconds (not including time for transducer replacement).

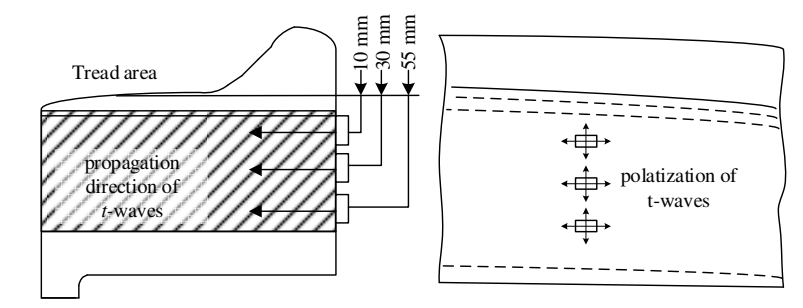

a

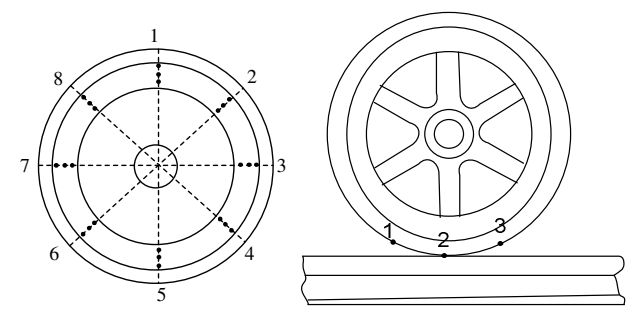

b

Fig. 3 A location EMA transducer: a) the width of wave propagation, $b$ ) on the circumference of the treads

\section{RESULTS OF THE TESTING}

Residual stresses in the process of wheel pair forming Measurements of the residual stresses in the tread were taken after every technological step of wheel pair joining including the following stages:

- in rough state;

- after turning of the fitting surface and the inner side surface adjoining to the wheel flange;

- after tread fit on the wheel center that was previously pressed on the wheel axle;

- after the final turning of the tread surface at a depth of $5 \mathrm{~mm}$ in the wheel pair.

The measurements were made in eight sections located on the rim and equally-spaced from each other and at the distance of $15,25,35,45,55 \mathrm{~mm}$ from the tread surface. The estimation results of residual stresses are given in Fig. 4.

Distributions of the residual stresses in the rough tread and in the tread after the turning in different sections have similar behavior. The stresses look like compressive ones near the tread surface, and they are getting tensile ones on drawing near the center. The dispertion of tensile stress level around the circumference has decreased to 10-50 MPa after the turning of the fitting surface.

The lowest values of the stresses are observed in the free tread near the tread surface. The stresses are higher and reach $100 \mathrm{MPa}$ in the central area of the tread. The tread fitting on the wheel center leads to significant increase of the tensile stresses due to the interference. After the pressing on the wheel center, the stresses are within the range from 200 to $250 \mathrm{MPa}$ near the tread surface and exceed $340 \mathrm{MPa}$ in the several sections of the central part (Fig. 4). The highest value of the interference equaled to $1.6 \mathrm{~mm}$ corresponds the stresses of 310-315 MPa.

The tread turning after the pressing does not change the residual stress level significantly. The distribution of the 
residual stresses around the tread circumference is considerably homogeneous and the variation does not exceed deviation from the averaged value which is equaled to $40 \mathrm{MPa}$.

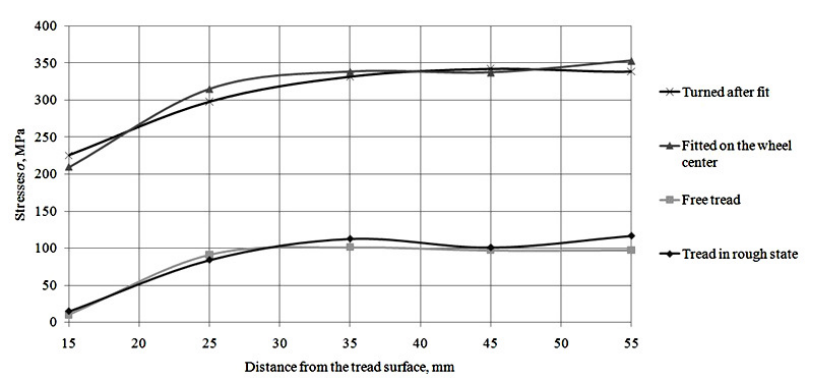

Fig. 4 Change of residual stresses throughout the thickness tread during the formation of wheels

\section{CONTROL OF THE RESIDUAL STRESSES IN THE PROCESS OF WHEEL PAIR REPAIR}

The estimation of the residual stresses was performed on a wheel pair after tread replacement due to their breaking. The broken treads were removed and the pressing of new treads on the wheel centers pressed on the wheel axle was carried out. The results of the stress measurement taken on two treads in one-wheel pair are illustrated in Fig. 5.

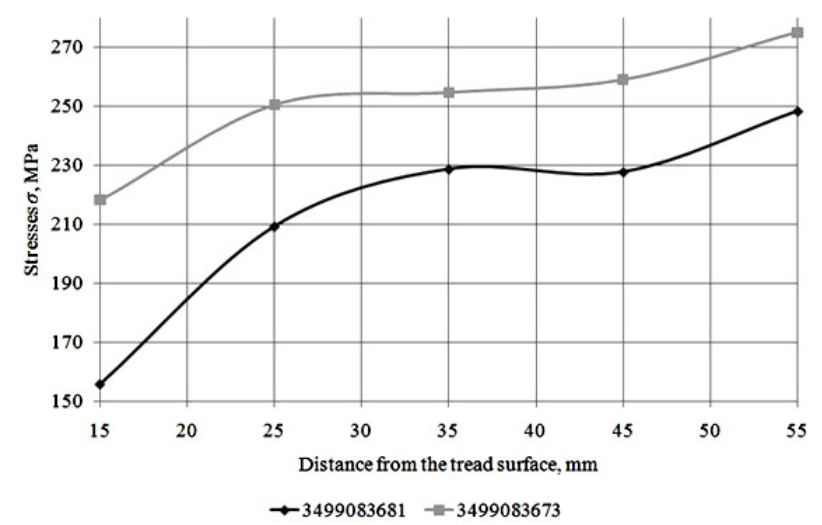

Fig. 5 The distribution of residual stresses throughout the thickness treads after servicing wheelset

The stresses are increasing from the tread surface to the seating area in both treads. At that the difference between the levels of the residual stresses in two treads in the same wheel pair is within the range from 50 to 100 MPa (Fig. 5). Such difference can lead to the inhomogeneous run-out of treads in the wheel pair.

\section{CONTROL OF THE RESIDUAL STRESSES UNDER LOCOMO- TIVE LOAD}

The measurement of the residual stresses is carried out on the treads of the wheels under locomotives. The measurements were taken in two sections: the first one was located directly in the place of contact with the rail track (section 5 Fig. 3), and the second one was at the distance equaled to the quarter of circumference (sections 4 and 6 Fig. 3). The results are given in the Fig. 6.

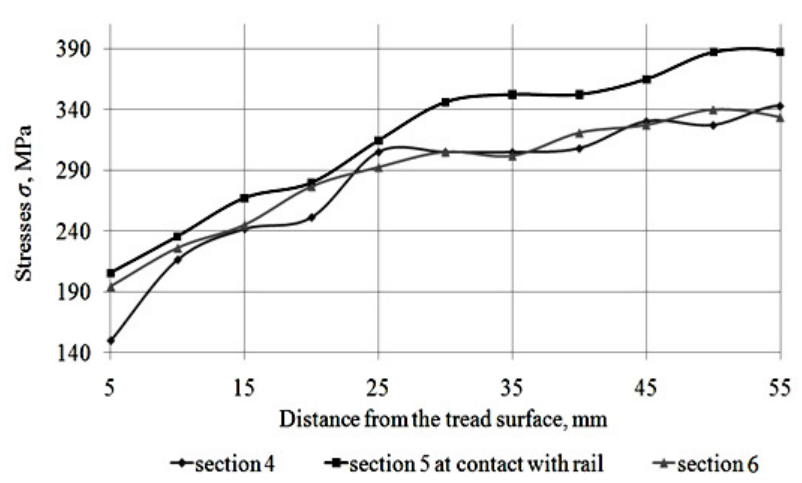

Fig. 6 The distribution of stress in tread under load locomotive

The tensile stresses from $160 \mathrm{MPa}$ near the tread surface and up to $400 \mathrm{MPa}$ near the seating area are observed in the tread pressed on the wheel center and located in the running gear of the first locomotive (Fig. 6a), and the stress level is higher (up to $430 \mathrm{MPa}$ ) in the place of contact with the rail track. The tensile stresses from $150 \mathrm{MPa}$ near the tread surface as well and up to $350 \mathrm{MPa}$ near the seating area are observed in the tread under the second locomotive (Fig. 6b), and the stress level is higher (up to $390 \mathrm{MPa}$ ) in the place of contact with the rail track.

\section{RELATION BETWEEN THE INTERFERENCE VALUE AND THE RESIDUAL STRESSES}

The interference values obtained according to the results of the stress evaluation by the acoustic technique for sampling of 30 treads is shown in Fig. 7.

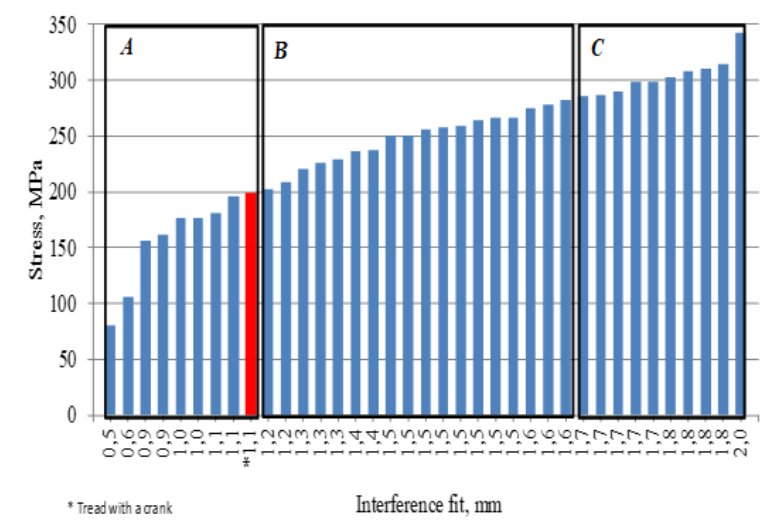

Fig. 7 The interference level that was obtained from the results of the acoustic method that determined by the measured stresses

Area "A» in Fig. 7 corresponds to the insufficient interference values obtained by the experimentally measured stresses. Low stress level near the fitting place on the wheel center in the area «A» is coming from relatively low values of the stresses over the whole tread section (the highest stress values do not reach $250 \mathrm{MPa}$ ).

Area « $\mathrm{B}$ " corresponds to the tread interferences according to technical requirements. The obtained interference and the corresponding residual stresses in the treads exceed the regulated values in area "C», it means that abruption of the tread can take place under cyclic operation loads in a presence of stress concentrator.

The distribution of the residual stresses in the treads around the circumference is considerably homogeneous and does not exceed $50 \mathrm{MPa}$. 


\section{CONCLUSION}

The measurement results of the residual stress in the treads through the thickness and around the circumference during different process stages of locomotive wheel pair forming based on the acoustoelasticity effect using the electromagnetic acoustic transducer are presented in this article.

The distribution of the residual stresses through thickness of the tread is obtained in its rough state, after the turning, after tread fitting on the wheel center, after the next turning and after fitting on the axle.

There are the lowest values of the stresses on the tread surface of free treads. The stresses reach $130 \mathrm{MPa}$ in the central area of the free thread.

The tread fitting on the wheel center leads to increase of the residual stresses due to interference. The residual stresses after pressing on the wheel center are equal to $210 \mathrm{MPa}$ on the tread surface and up to $350 \mathrm{MPa}$ in the central area and near the fitting area.

The difference between the residual stress levels after replacement of the treads in one-wheel pair is equal to 50-100 $\mathrm{MPa}$ on the average. Generally, the stresses do not exceed $280 \mathrm{MPa}$. The residual stresses of the wheel treads under locomotive load were also measured. The tensile stresses in the tread of the first locomotive are from $160 \mathrm{MPa}$ near the tread surface and up to $400 \mathrm{MPa}$ near the fitting area, but the stress level is higher (up to $430 \mathrm{MPa}$ ) in the place of contact with a rail track. The tensile stresses of the treads under the second locomotive are from $150 \mathrm{MPa}$ near the tread surface as well up to $350 \mathrm{MPa}$ near the fitting, but the stress level is higher (up to $390 \mathrm{MPa}$ ) in the place of contact with the rail track.

According to the level of stresses near the area of tread fitting on the wheel centers, it is possible to monitor the density of fitting and to avoid crank and creeping as well as rupture of the tread under high level of the stresses during the operation of a rolling stock.

\section{ACKNOWLEGEMENT}

The reported study was funded by Ministry of Education and Science of the Russian Federation according to the project no. 3.5705.2017/6.7 of the state order for Kalashnikov Izhevsk State Technical University for a period of 2017-2019, section "Management of scientific research".

\section{REFERENCES}

[1] Kamyshev, A.V., Nikitina, N.E., Smirnov, V.A. (2010). Measurement of the residual stresses in the treads of railway wheels by the acoustoelasticity method. Russian Journal of Nondestructive Testing, 46 (3), 189-193.

[2] Murav'ev, V. V., Volkova, L. V. (2013). Evaluation of the interference value for the treads of locomotive wheels by the acoustic elasticity method. Russian Journal of Nondestructive Testing, 49 (9), 524-529.

[3] Croccolo, D., De Agostinis, M., Ceschini, L., Morri, A., Marconi A. (2013). Interference fit effect on improving fatigue life of a holed single plate. Fatigue \& Fracture of Engineering Materials \& Structures, 36 (7), 689-698.

[4] Mädler, K., Geburtig, T., Detlev U. (2016). An experimental approach to determining the residual lifetimes of wheelset axles on a full-scale wheel-rail roller test rig. International Journal of Fatigue, 86, 58-63.
[5] Motova, E.A., Nikitina, N.E., Tarasenko, Yu. P. (2013). Concerning the Possibility of Examining Compressor Blades according to Attenuation and Speed of Ultrasound. Journal of Machinery Manufacture and Reliability, 42 (4), 335-340.

[6] Kostin V.N., Vasilenko O.N., Filatenkov D.Yu., Chekasina Yu.A., Serbin E.D. (2015). Magnetic and magnetoacoustic testing parameters of the stressed-strained state of carbon steels that were subjected to a cold plastic deformation and annealing. Russian Journal of Nondestructive Testing, 51 (10), 624-632.

[7] Filinov V.V., Kuznetsov A.N., Arakelov P.G. (2017). Monitoring stressed state of pipelines by magnetic parameters of metal. Russian Journal of Nondestructive Testing, 53 (1), 51-61.

[8] Wentao Song, Chunguang Xu, Qinxue Pan, Jianfeng Song (2016). Nondestructive testing and characterization of residual stress field using an ultrasonic method. Chinese Journal of Mechanical Engineering, 29 (2), 365-371.

[9] Yashar Javadi, Seyed Hatef Mosteshary (2015). Evaluation of Welding Residual Stress in a Nickel Alloy Pressure Vessel using the Ultrasonic Stress Measurement Technique. Materials Evaluation, 73 (6), 862-868.

[10] Allen, D.R., Sayers, C.M. (1984). The measurement of residual stress in textured steel using an ultrasonic velocity combinations technique. Ultrasonics, 22 (4), 179-188.

[11] Chunguang Xu, Wentao Song, Qinxue Pan, Huanxin Li, Shuai Liu. (2015). Nondestructive Testing Residual Stress Using Ultrasonic Critical Refracted Longitudinal Wave. Physics Procedia, 70, 594-598.

[12] Uglov A.L., Khlybov A.A. (2015). On the inspection of the stressed state of anisotropic steel pipelines using the acoustoelasticity method. Russian Journal of Nondestructive Testing, 51 (4), 210-216.

[13] Smirnov A.N., Knyazkov V.L., Abakov N.V., Ozhiganov E.A., Koneva N.A., Popova N.A. (2018) Acoustic evaluation of the stress-strained state of welded carbon steel joints after different modes of heat input. Russian Journal of Nondestructive Testing, 54 (1), 37-43.

[14] Hirao M., Ogi H. Electromagnetic Acoustic Transducers: Noncontacting Ultrasonic Measurements Using EMATs. Tokyo: Springer Japan, 2017. 380 c.

[15] Murav'ev V.V., Volkova L.V., Platunov A.V., Kulikov V.A. (2016). An electromagnetic-acoustic method for studying stress-strain states of rails. Russian Journal of Nondestructive Testing, 52 (7), 370-376.

[16] Murav'ev V.V., Tapkov K.A. (2017). Evaluation of StrainStress State of the Rails in the Production. Devices and Methods of Measurements, 8 (3), 236-245.

[17] Murav'ev V.V., Murav'eva O.V., Petrov K.V. (2017). Connection between the properties of $40 \mathrm{kh}$-steel bar stock and the speed of bulk and Rayleigh waves. Russian Journal of Nondestructive Testing, 53 (8), 560-567.

[18] Murav'ev V.V., Volkova L.V., Platunov A.V., Buldakova I.V., Gushchina L.V. (2018) Investigations of the structural and strain-stress state of the rails of current production by the acoustic elasticity method. Bulletin of Kalashnikov ISTU, 21(2), 13-23.

[19] Murav'ev V.V., Murav'eva O.V., Petrov K.V. (2018) Contactless electromagnetic acoustic techniques of diagnostics and assessment of mechanical properties of steel rolled bars. Materials physics and mechanics, 38 (1), 4853.

[20] Dovica, M., Busa, J., Palencar, R., Duris, S., Soos, L., Vrba, I., Kelemenova, T., Skovranek, T. (2013). Comparison of methods for analysis of deviations from roundness. Measurement Techniques, 56 (9), 1021-1025. 
[21] Jančárik, V., Hartáanský, R., Slížik, J., Mierka, M., Halgoš,J., Hallon,J., Hricko, J. (2019). Autonomous sensor of electromagnetic field. In Review of Scientific Instruments. Vol. 90, Iss. 6 Art. No. 64705.

[22] Hornik, J.; Peslova, F.; Krum, S. (2016) Selection of basic input variables for computational modeling of brake shoes. Procedia Engineering, 136, 300-305.

[23] Horník, J., Zuna, P., Málek, J. (2017) Evaluation of changes of mechanical properties of selected $\mathrm{Cr}$-Ni-Mo steels for heavy forgings during long time annealing. Materials Science Forum, 891, 149-154.
[24] Slí̌ik, J., Hart́anský, R. (2013). Metrology of Electromagnetic Intensity Measurement in Near Field. In Quality Innovation Prosperity. Vol. 17, Iss. 1 (2013), pp. 57-66.

[25] Budenkov G.A., Korobeinikova O.V. (2009) Influence of the chemical composition and temperature of metals on the efficiency of electromagnetic-acoustic transformation. Russian Journal of Nondestructive Testing. 45 (4), 252-258.

\footnotetext{
Vitaly V. Muravev

ORCID ID: 0000-0001-8590-1382

Kalashnikov Izhevsk State Technical University,

Faculty of Instrumentation Engineering,

Department of Instruments and Techniques of measurements, testing and diagnostics, 7 Studencheskaya Str., Izhevsk, 426069, Udmurt Republic, Russian Federation
}

\section{Olga V. Muraveva}

ORCID ID: 0000-0003-3442-8163

Kalashnikov Izhevsk State Technical University,

Faculty of Instrumentation Engineering,

Department of Instruments and Techniques of measurements, testing and diagnostics, 7 Studencheskaya Str., Izhevsk, Udmurt Republic, Russia, 426069

Udmurt Scientific Center of Ural Branch of Russian Academy of Sciences,

34 T. Baramzinoy Str., Izhevsk, 426067, Udmurt Republic, Russian Federation

e-mail:pmkk@istu.ru

\section{Ludmila V. Volkova}

ORCID ID: 0000-0001-5128-6465

Kalashnikov Izhevsk State Technical University,

Faculty of Instrumentation Engineering,

Department of Instruments and Techniques of measurements, testing and diagnostics, 7 Studencheskaya Str., Izhevsk, 426069, Udmurt Republic, Russian Federation

\section{Milan Sága}

University of Žilina, Faculty of Mechanical Engineering

Department of Applied Mechanics

Univerzitná 8215/1, 01026 Žilina, Slovak Republic

\section{Zuzana Ságová}

University of Žilina, Faculty of Mechanical Engineering

Department of Automation and Production Systems

Univerzitná 8215/1, 01026 Žilina, Slovak Republic 